\title{
X-ray phase-contrast imaging
}

\author{
Marco Endrizzi ${ }^{\mathrm{a}}$ \\ ${ }^{a}$ Department of Medical Physics and Biomedical Engineering, University College London, \\ Gower Street, London WC1E 6BT, United Kingdom
}

\begin{abstract}
X-ray imaging is a standard tool for the non-destructive inspection of the internal structure of samples. It finds application in a vast diversity of fields: medicine, biology, many engineering disciplines, palaeontology and earth sciences are just few examples. The fundamental principle underpinning the image formation have remained the same for over a century: the X-rays traversing the sample are subjected to different amount of absorption in different parts of the sample. By means of phase-sensitive techniques it is possible to generate contrast also in relation to the phase shifts imparted by the sample and to extend the capabilities of X-ray imaging to those details that lack enough absorption contrast to be visualised in conventional radiography. A general overview of $\mathrm{X}$-ray phase contrast imaging techniques is presented in this review, along with more recent advances in this fast evolving field and some examples of applications.
\end{abstract}

Keywords: X-ray; phase-contrast; imaging

\section{1. Introduction}

2 The use of X-rays for imaging the internal structure of samples quickly spread

3 around the world soon after the first X-ray radiograph was taken by Wilhelm

4 Conrad Röntgen towards the end of 1895 [1]. Great improvements have con-

5 stantly been made throughout the last century both with regard to the X-ray

6 generators and to the image receptors, including transformative advances such

Email address: m.endrizzi@ucl.ac.uk (Marco Endrizzi) 
7 as the introduction of tomography [2]. X-ray imaging is nowadays a standard tool in many diverse fields and disciplines, ranging from medical sciences to materials engineering and including quality control in industry as well as security screening.

Despite tremendous progress, the fundamental working principle has remained unchanged for over a century: contrast is generated by differences in the absorption of the X-rays within the sample. This can provide excellent results when relatively high attenuation exists, but leads to poor image quality when the sample is weakly absorbing. Generally speaking, this occurs for materials and tissues composed of light elements. The possibility of performing phase-based imaging bears the potential of making visible what would be undetectable with the conventional method for these classes of samples.

A number of reviews is already available on this topic, including a focus on the evolution and relative merits of these imaging techniques [3, on the transition from synchrotron to conventional sources [4, on medical applications [5] with the translation towards clinical implementation 8 the imaging of the breast [9], and also on materials science applications [10, 11].

The aim of this review is to present a general overview of the essentials Xray phase-contrast imaging techniques in the hard X-ray regime, as well as some examples of use in applied investigations. An in-depth discussion is dedicated to the principles and recent advances of edge illumination, a technique that has been intensively investigated in the recent time by our group for the translation of these advanced X-ray imaging techniques into table-top instrumentation that can be compatible with clinical or industrial environments.

\section{Methods}

$\mathrm{X}$-ray imaging is a general term that embraces an extremely wide set of techniques that are used to produce a representation of the sample under inspection. In order to describe phase-contrast X-ray imaging techniques, we will start from the basis of the more conventional, or absorption-based, approach. 


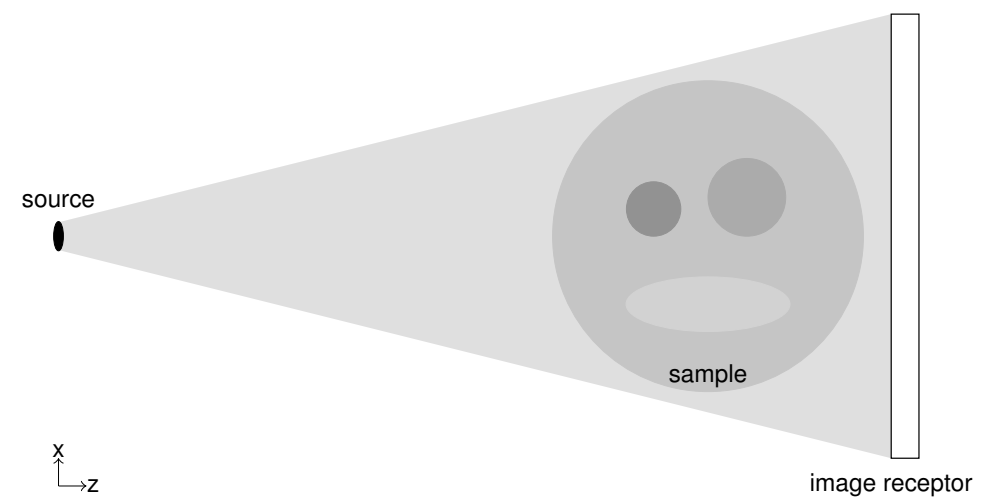

Figure 1: Schematic of the set-up for conventional X-ray imaging: the image receptor looks directly at the radiation source and through the sample.

$52 \quad 13$

$$
I(x, y)=I_{0}(x, y) \exp \left[-\left(\mu_{o}^{\lambda}-\mu_{h}^{\lambda}\right) T_{o}(x, y)\right]
$$




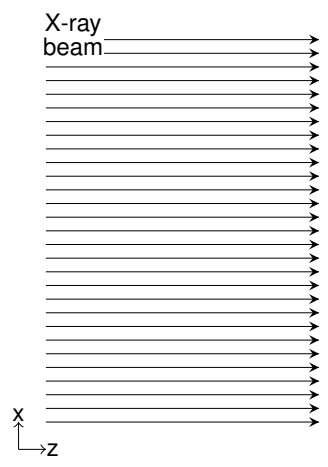

(a)

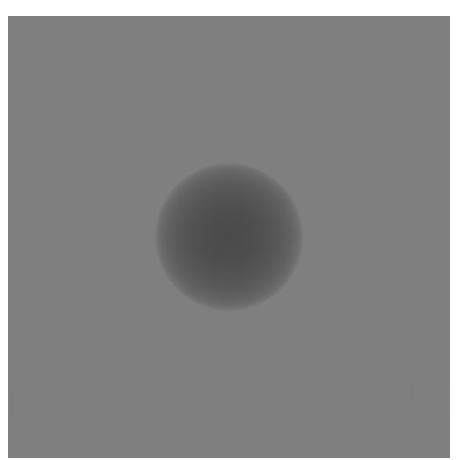

(b)

Figure 2: (a) simple model for the generation of contrast in absorption-based X-ray imaging. (b) corresponding image recorded represented as the two dimensional distribution of intensity, which was computed by using the X-Tract software [12].

where $T_{o}(x, y)$ is the projected thickness of the object on the $(x, y)$ plane and $I_{0}(x, y)$ is the intensity incident on the sample. For the simple case presented above this can be calculated analytically. Let us assume a sphere of radius $r$ and centred in the origin. The projected thickness of the sphere, measured by a line profile running across the centre of the sphere $(y=0)$, is given by the real part of

$$
T(x)=2 \sqrt{r^{2}-x^{2}} .
$$

We can then calculate the corresponding intensity profile by using Equation 1 In order to do so we need to specify the working energy (30 keV), the materials (aluminium for the sphere and water for the embedding material) and we further assume a constant incident intensity $I_{0}(x, y)=1$.

It is often the case, for example when using conventional laboratory sources such as X-ray tubes, that the radiation is polychromatic and its spectrum extends over a range of several tens of keV. This can be included in Equation 1 by an integration over the energy that takes into account the energy dependence of the source spectrum $I_{0}(\lambda)$, of the attenuation coefficient $\mu^{\lambda}$ and of the detector 
response $\mathcal{D}(\lambda)$

$$
I(x, y)=\int d \lambda I_{0}(x, y ; \lambda) \exp \left[-\left(\mu_{o}^{\lambda}-\mu_{h}^{\lambda}\right) T_{o}(x, y)\right] \mathcal{D}(\lambda) .
$$

69

Each monochromatic component of the X-ray beam contributes independently to the contrast, with a weight that is equal to the relative probability of emission and detection, and with the attenuation coefficient characteristic of that particular energy (for example see [14).

\subsection{Phase-contrast imaging}

The phase of the waves travelling through the sample contributes to the modulation of the detected intensity in an X-ray phase-contrast imaging system.

This can be described by means of the complex refractive index [15]

$$
n=1-\delta+i \beta
$$

where the decrement to unity $\delta$ governs the phase shifts while $\beta$ the absorption. Away from absorption edges, and in the region where the photoelectric effect dominates absorption, $\delta$ and $\beta$ can be expressed as functions of the electron density $\rho$ and of the radiation wavelength in the following way [16]

$$
\begin{aligned}
\delta(\lambda) & =\rho \frac{r_{e} \lambda^{2}}{2 \pi} \\
\beta(\lambda) & =\mu(\lambda) \frac{\lambda}{4 \pi}
\end{aligned}
$$

where $r_{e}$ is the classical electron radius. It is worth noting that $\delta$ is typically larger than $\beta$. By taking for example water at $30 \mathrm{keV}$, we obtain $\delta \approx 2.56 \cdot 10^{-7}$ and $\beta \approx 1.36 \cdot 10^{-10}$. Another key difference between the two parameters is their dependence on the X-ray energy $E$ : $\beta$ decreases approximately with $E^{-4}$ while $\delta$ approximately as $E^{-2}$. Real and imaginary parts of the complex refractive indices of two materials, one composed of light elements and one composed of heavier elements, are plotted in Figure 3 in the energy range between 10 and $120 \mathrm{keV}$ for illustration purposes.

The phase shift imparted by the sample to the X-ray wave is given by

$$
\Phi(x, y ; \lambda)=-k \int_{\mathcal{O}} d z \delta(x, y, z ; \lambda)
$$




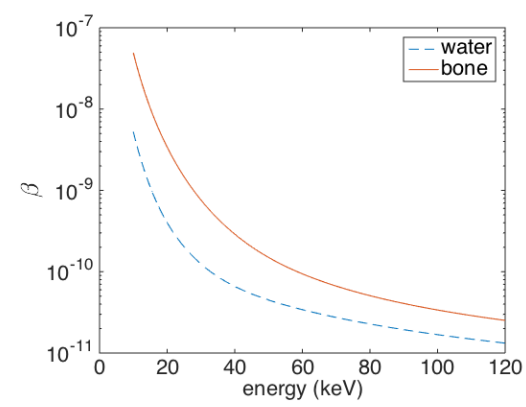

(a)

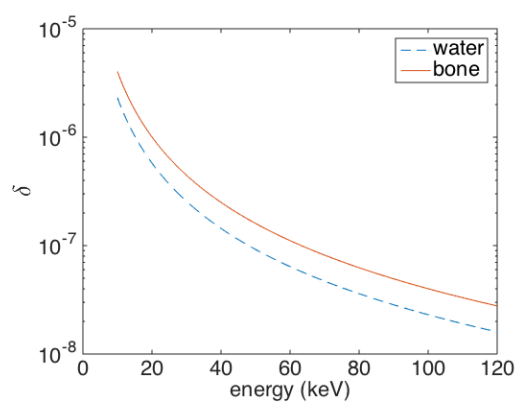

(b)

Figure 3: Complex index of refraction for water and bone as a function of X-ray energy: (a) $\beta$ and (b) $\delta$. Bone composition was taken from the ICRU report [17.

where the integration is carried out over the extent of the object $\mathcal{O}$ along the optical axis, and this Equation can be considered valid for propagation through thin objects, for which the projection approximation holds [15].

Referring to previous example of a simple sphere composed of a single material, the transmission and phase shift of the sample become

$$
\begin{aligned}
I(x, y ; \lambda) & =\exp \left[-\frac{4 \pi \beta(\lambda)}{\lambda} T(x, y)\right] \\
\phi(x, y ; \lambda) & =-k \delta T(x, y)
\end{aligned}
$$

where a single energy was used for the X-ray beam.

\section{X-ray phase-contrast imaging}

It is not possible to directly measure the phase of electromagnetic waves at optical frequencies and above, however, phase effects can play a significant role in the image formation also in the hard X-ray regime. Phase-contrast imaging techniques exploit the phase perturbations introduced by the sample to modulate the intensity recorded at the image receptor, in such a way that these effects can be detected and interpreted.

A summary of these techniques will be presented in the following sections. The classification is inevitably made afterwards, and it is therefore natural that 
Figure 4. Phase-coherent beams are formed by dividing the incoming X-ray

the categories will be appropriate in certain cases while less accurate in others. X-ray phase-contrast imaging techniques are evolving fast, and a large degree of contamination often exists across different approaches. A classification based on the most prominent characteristics of the experimental set-ups and their working principles was chosen here as the main criterion for distinction between different approaches.

\subsection{Interferometry}

The first example of X-ray phase-contrast imaging method is the X-ray interferometer [18, 19] which was built form a monolithic crystal and used a LaueLaue-Laue configuration. A schematic representation of this device is shown in

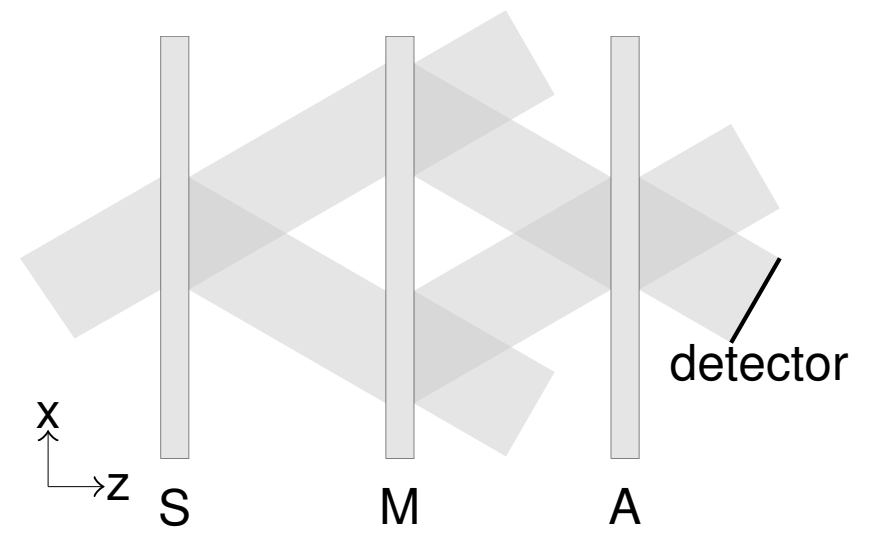

Figure 4: Top view of an X-ray interferometer.

115 4 Phase-coherent beams are formed by dividing the incoming X-ray

beam at the beam splitter $\mathrm{S}$ and successively at the transmission element $\mathrm{M}$, they meet again at the analyser A where an atomic-scale standing wavefield is formed [20]. In an ideal scenario, where the wave is perfectly planar and the crystal free of imperfections, the field would be perfectly uniform until a sample is introduced in one of the arms of the interferometer. The image would then record the phase changes induced by sample, modulo $2 \pi$. In practice, local phase shifts, arising for example from strain and defects in the crystal, will generate interference patterns that will be superimposed to the modulations imposed by 

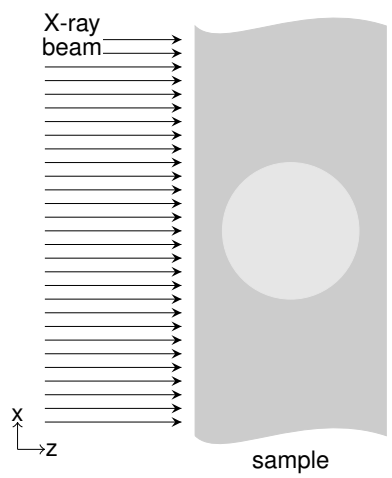

(a)

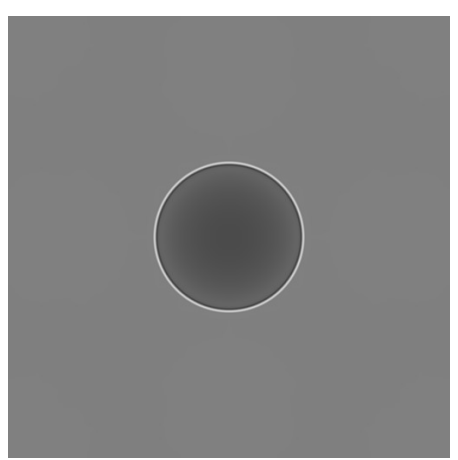

(b)

Figure 5: (a) simple model for the generation of a phase contrast image with the free space propagation technique. (b) corresponding image recorded represented as the two dimensional distribution of intensity, calculated by using the X-Tract software [12].

the sample. It is also possible to insert a known phase modulation in one arm, as for example a linear phase ramp imposed by using a wedge, while the sample under study is placed in the other arm. The linear phase ramp will generate a series of linear fringes in the intensity recorded at the detector, hence the name of fringe scanning method [21].

Following the first demonstration of the working principle and pioneering imaging experiments [22, 23], this method was used for biomedical imaging experiments [24 27] to study different tissue types such as breast, brain and blood 28 30].

\subsection{Free-space propagation}

Free-space propagation techniques are perhaps the ones requiring the simplest set-up because the introduction of an appropriate propagation distance $R_{2}$ between the sample and the image receptor can be sufficient to make phase effects detectable (see Figure 5). Early works demonstrating this possibility date back to the mid '90s and used both monochromatic and collimated synchrotron radiation [31, 32 and polychromatic radiation from a microfocus X-ray tube [33. This phenomenon can be interpreted in terms of Fresnel diffraction and 
key features of this approach to imaging can be identified by referring to the following expression [15, 33, 34]

$$
I(x, y ; M, \lambda)=\frac{I_{0}}{M^{2}}\left[1+\frac{R_{2} \lambda}{M 2 \pi} \nabla_{\perp}^{2} \phi\left(x, y ; R_{1}, \lambda\right)\right]
$$

that describes the intensity distribution a the image receptor plane from a pure phase object. $M=\left(R_{1}+R_{2}\right) / R_{1}$ is the geometrical magnification. The contrast from a pure phase object vanishes when $R_{2} \rightarrow 0$, which is the typical condition for conventional (contact) radiography and the phase term is directly proportional to the propagation distance $R_{2}$. Another feature of interest is that the monochromaticity of the radiation is not essential for this type of imaging. A necessary condition, however, is that the radiation must have a certain degree of spatial coherence [13]:

$$
l_{c}=\frac{\lambda R_{1}}{\sigma_{s} 2 \sqrt{2 \log 2}}
$$

where $\sigma_{s}$ is the standard deviation of the source intensity distributon. The coherence length $l_{c}$ has to be comparable to or larger than the inverse spatial frequency of the feature of interest [35] in order to obtain signifcant phase contrast. In practice this means that the source has to be relatively small or that the object must be placed at a relatively large distance $R_{1}$ from it. Another requirement is that the imaging system must have spatial resolution high enough to not wash out the interference fringes. This is conveniently summarised by the following expression [36, 37]

$$
\sigma_{t}^{2} \approx\left(1-\frac{1}{M}\right)^{2} \sigma_{s}^{2}+\frac{\sigma_{d}^{2}}{M^{2}}+\sigma_{m}^{2}
$$

where $\sigma_{t}$ and $\sigma_{d}$ are the standard deviations of the system's and of the detector's point spread function, respectively. Another point to be noted is that the diffraction term

$$
\sigma_{m}=\frac{1}{2} \sqrt{\frac{\lambda R_{2}}{2}}
$$

becomes less significant for increasing X-ray energies.

The intensity projection image, acquired with a certain propagation distance between the sample and the detector, will contain a mixture of contributions 
from both the absorption and the phase shifts in the sample. Other experimental parameters, like the X-ray energy, the geometrical magnification, the radiation coherence and the system resolution, determine the modulation of intensity at the detector. The process that aims at making this type of imaging quantitative by calculating phase and amplitude at the exit surface of the sample is called phase retrieval. Methods to achieve this, in the case of non-interferometric hard X-ray imaging techniques, started developing soon after the first experiments 38 41, also including polychromatic X-ray beams [42] and even exploiting different energies for the phase retrieval process itself [43]. Quantitative retrieval algorithms are also a fundamental component for accurate three-dimensional reconstructions [44 46]. In general terms, the determination of both amplitude and phase requires more than a single measurement (for example by changing the propagation distance or by changing the energy) unless some constraints can be imposed on the sample. Quantitative phase retrieval can be performed from a single defocus distance by requiring homogeneity of the sample [47]: although this might not always be strictly satisfied, it is a very reasonable approximation in many cases of interest (e.g. soft tissue samples) and this approach often delivers high quality projections and reconstructions.

Applications of free-space propagation X-ray phase-contrast imaging are vast and definitely too many to be covered here. We will limit this discussion to few highlights like micro- and nano-tomography applications [48 54, lung imaging [55 59] and breast tissue imaging 60, 61 including in-vivo 62, 64.

\subsection{Analyser based imaging}

Analyser-based methods make use of crystals both for beam preparation and analysis. The crystal arrangement preceding the sample is used to monochromatise and collimate the incoming X-ray beam while the one preceding the detector serves as a fine angular filter. A typical synchrotron experimental setup is sketched in Figure 6. The X-ray beam is usually wide enough to cover the extent of the sample along the $x$ direction while scanning along $y$ is often necessary to build a two-dimensional image. The intensity at the detector is 


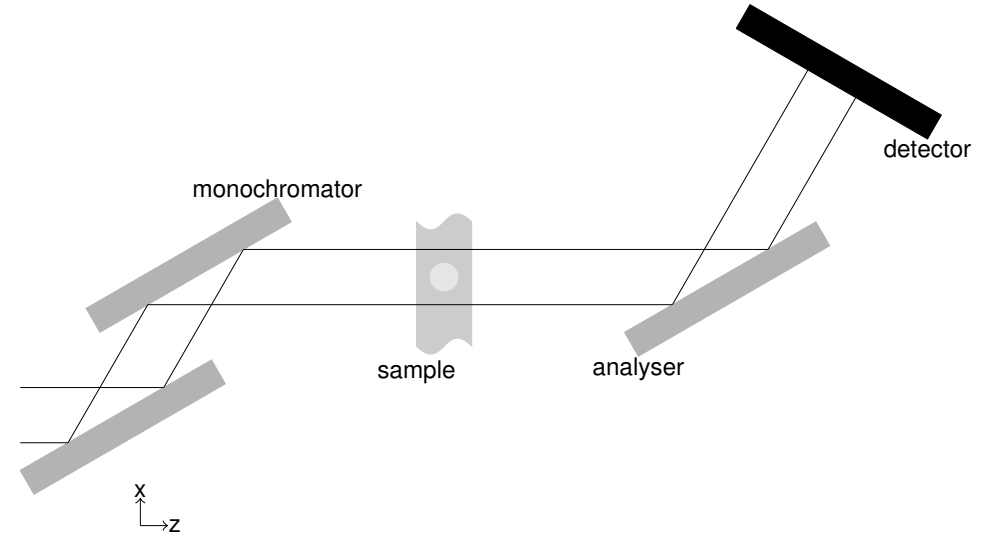

Figure 6: Example of analyser based imaging set-up.

modulated by changing the angle of incidence of the X-ray beam on the second (analyser) crystal (see Figure 7a). This characteristic curve takes the name of rocking curve and it is key in the image formation process. It results from the combination of the reflectivity curves of both the monochromator and the analyser crystal with a contribution arising from the beam divergence [65]. When the system is tuned in such a way that roughly half of the intensity reaches the detector (at full width half maximum of the rocking curve), small changes in the direction of the propagation of the X-rays due to refraction in the sample are transformed into intensity changes at the image receptor. The change in direction of propagation is directly proportional to the gradient of the sample's phase [13]

$$
\theta_{R}=\frac{\lambda}{2 \pi} \frac{\partial \phi(x, y)}{\partial x}
$$

and an imaging system where contrast is proportional to the refraction angle is often referred to as differential phase-contrast imaging system. The image recorded in the case of the sphere sample is shown in Figure $7 \mathrm{~b}$. The X-rays going through the centre of the sphere experience little or no refraction at all, therefore their direction of propagation is not changed and they are transmitted by the analyser with the same probability of the radiation that is not hitting the sample. The image contrast in this region of the sample is mainly due to 


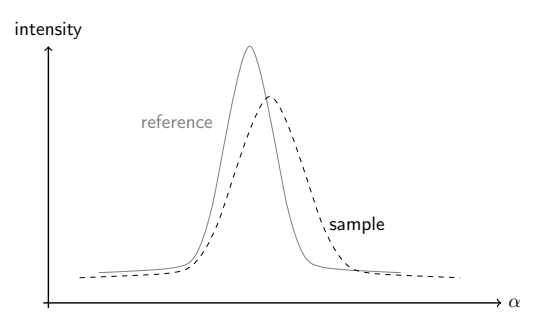

(a)

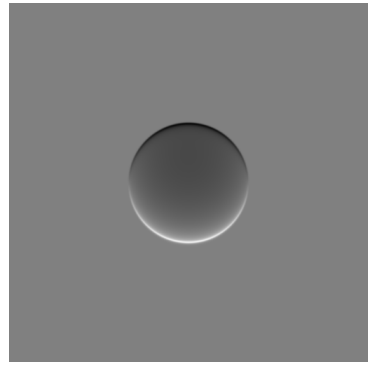

(b)

Figure 7: Image formation principle in an analyser-based system. (a) typical rocking curve: intensity recorder at a fixed position in the detector plane as a function of the "rocking" angle $\alpha$ of the analyser crystal. (b) intensity recorded at the detector when the analyser crystal is set at fixed angle, in such a way that $50 \%$ of the intensity is transmitted (obtained by using the X-Tract software [12]).

X-ray absorption within the sample. Refraction increases while approaching the sphere's edges, where the change in the direction of propagation is maximum. Because X-rays are deflected away from the beam axis (a glass sphere in air acts as a diverging lens in the $\mathrm{X}$-ray regime), the angle of incidence of the radiation on the analyser will be changed in two opposite ways at the two edges of the sphere. On one side, this will result in a higher probability of transmission through the analyser, while it will translate into a smaller transmission probability on the opposite side. This is the mechanisms at the basis of the generation of the dark and bright fringes of Figure $7 \mathrm{~b}$

Early implementations of this technique for imaging fusion pellets are those of Goetz and Forster 66, 67. This approach became increasingly popular after 1995 [68, 69] when methods to quantitatively separate phase and absorption contributions were developed [70, 71. This method is intrinsically sensitive to the phase gradient in a single direction only and an additional measurement is tipycally required to quantify the other component [72. Another key development that soon followed was the possibility to quantify the effect of the scattering in the sample on the width of the rocking curve, which was put in relation to sub-pixel scale features 73 77. This was also extended for applica- 


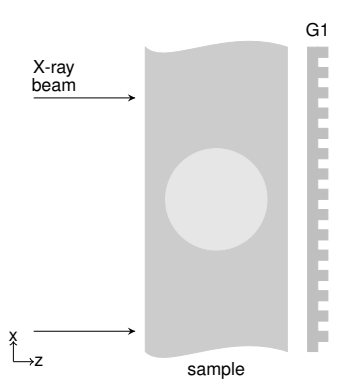

(a)
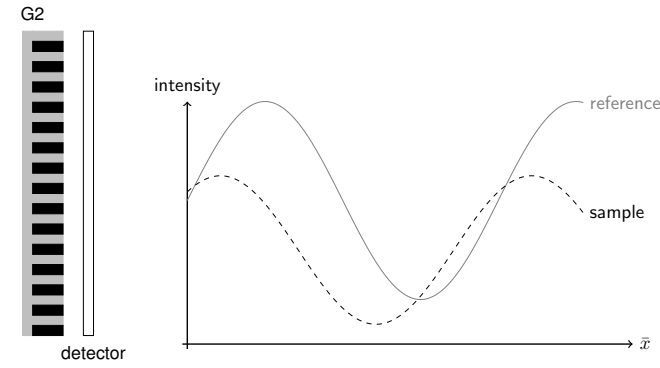

(b)

Figure 8: Example of grating based imaging set-up. (a) typical arrangement where the phase grating is placed after the sample and the (analyser) amplitude grating immediately precedes the detector. (b) intensity recorded at a fixed $(x, y)$ position in the detector plane as a function of the scanning position of one grating relative to the other, along the $x$ direction.

tions to tomography [78. Methods for retrieving phase information from the simultaneous acquisition of two images have been developed for the case of Laue analyser 79.

Some examples of the many applications of analyser based techniques in the medical field [80] are: cartilage [81,83], musculoskeletal 84] and breast tissue [65, 85, 87] imaging and dynamic tracking of micro-bubble concentrations [88, 89.

\subsection{Grating based imaging}

Grating-based imaging methods make use of periodic structures to condition and analyse the X-ray beam. A typical embodiment of this technique is sketched in Figure 8a where the X-ray beam traverses the sample that modulates its amplitude and imposes phase shifts. It is then passed through the phase grating $G_{1}$ and analysed by the absorption grating $G_{2}$ immediately before the image receptor. If one of the two grating is laterally scanned (along $x$ ) without the sample in the beam, a modulated intensity curve is detected in each pixel. This is often referred to as the phase-stepping curve. When the sample is present in the beam, this curve is modified in three ways, as depicted in Figure $8 \mathrm{~b}$. The relative reduction of the baseline is the conventional absorption image, the lateral shift of 
the curve represents the differential phase contrast and the reduction of visibility is linked to the scattering in the sample, or dark-field imaging. This can be expressed quantitatively by writing the intensity oscillations recorded at a point $(x, y)$

$$
\begin{aligned}
I(\bar{x} ; x, y) & =\sum_{i} a_{i}(x, y) \cos \left(\frac{2 \pi i \bar{x}}{p_{2}}+\Phi_{i}(x, y)\right) \\
& \approx a_{0}(x, y)+a_{1}(x, y) \cos \left(\frac{2 \pi i \bar{x}}{p_{2}}+\Phi_{1}(x, y)\right) a s
\end{aligned}
$$

where $p_{2}$ is the period of $G_{2}$ and $a_{i}$ and $\Phi_{i}$ are the amplitude and phase coefficient, respectively. The images of the sample are recontstructed by comparing the phase-stepping curves recorded without ${ }^{w}$ and with ${ }^{o}$ the sample in the beam 90. The transmission image, analogous to the one obtained in conventional radiography, is given by

$$
T(x, y)=a_{0}^{o}(x, y) / a_{0}^{w}(x, y) .
$$

8 taking the difference $\nabla_{x} \phi(x, y)=\nabla_{x}^{o} \phi(x, y)-\nabla_{x}^{w} \phi(x, y)$, and by considering that

$$
\nabla_{x} \phi(x, y)=\frac{p_{2}}{\lambda d} \Phi_{1}(x, y)
$$

where $d$ is the distance between $G_{1}$ and $G_{2}$. Dark-field images are obtained by first computing the normalized oscillation amplitude

$$
\begin{aligned}
V^{w}(x, y) & =\frac{I_{\max }^{w}(x, y)-I_{\min }^{w}(x, y)}{I_{\max }^{w}(x, y)+I_{\min }^{w}(x, y)} \\
& =\frac{a_{1}^{w}(x, y)}{a_{0}^{w}(x, y)}
\end{aligned}
$$

and then by taking the ratio of this quantity, with and without sample in the beam

$$
\begin{aligned}
V(x, y) & =\frac{V^{o}(x, y)}{V^{w}(x, y)} \\
& =\frac{a_{1}^{o}(x, y) a_{0}^{w}(x, y)}{a_{1}^{w}(x, y) a_{0}^{o}(x, y)}
\end{aligned}
$$


which does not show changes $(V(x, y)=1)$ for samples with negligible or absent small-angle scattering and is reduced $(V(x, y)<1)$ when scattering occurs.

Introduction of grating-based techqniques could be dated back to early '90s [91, 92] with experiments following few years later 93 97]. A breakthrough for the diffusion of this technique was the introduction of a third grating that enabled the use of low brilliance sources [98, tomography [99] and dark-field [100] or scattering imaging were also developed soon aftwerwards with a threegrating setup. An alternative method was subsequently proposed for differential phase-contrast imaging with weakly coherent hard X-rays 101. Quantitative three-dimensional dark-field imaging was then devoloped for these grating-based imaging set-ups [102, 103]. The simultaneous determination of the two components of the phase gradient, by means of gratings structured in two dimensions, has also been discussed [104 107]. Another important development is the inverse geometry 108 which can enable compact Talbot-Lau interferometry setups [109]. A much more detailed review of advances and milestones of grating-based X-ray phase-contrast imaging can be found in a recent review [90. A recent and very promising development on this front was the successful fabrication of grating structures with approximately one order of magnitude finer pitch [110] and their application for the enhancement of table-top imaging systems [11]. Albeit based on gratings, the working principle of this approach is different from that of the more conventional grating-based interferometry and it is best understood under the concept of univesal moiré effect 112. This eliminates the need for an absorption grating and enables the realization of a polychromatic far-field interferometer that can overcome the limitations in sensitivity and dose efficiency of more conventional bench-top interferometers 112 .

An extremely wide spectrum of application exists also for grating based imaging techniques, examples are: breast tissue [113 115], brain tumour [116], cartilage [117 120], and lungs [121, 122]. A fairly recent review exists that is fully dedicated to this topic [123]. 


\subsection{Tracking based methods}

Another broad category of X-ray phase-contrast imaging techniques stems from the observation that it is possible to measure the sample absorption, refraction and scattering by imposing a known structure to the radiation field and by directly tracking its modifications. In general terms, an overall reduction of the structured beam intensity can be traced back to absorption of the radiation within the sample, while the spatial distortions of the known intensity patterns are used to infer the phase shifts imposed by the sample to the wavefront.

The introduction of this approach may be traced back to the '90s [124, 125] with experiments following several years later. The structuring could be imposed by using a lenslet array [126], a microprobe [127], an absorption grid [128[130, a phase grating [131] or a speckle pattern [132, 133] and the distortions imposed by the sample can be tracked by using a high-resolution detector, also in combination with sub-pixel resolution analysis [134] or by using Fourier-based analysis [135]. These approaches can be extended to two-dimensional sensitivity [136 138, to include dark-field contrast [139, 140] and directional dark-field imaging [141 143]; as well as three-dimensional imaging with tomography [142, 144 .

Applications of tracking based techniques include: bone imaging [145], dynamic airways imaging [146, 147] and metrology [142, 148, 149].

\section{Edge illumination}

Edge illumination X-ray phase-contrast imaging has been investigated in the recent years as a possible way forward for the translation of phase-sensitive imaging techniques into mainstream applications. Edge illumination was initially developed in synchrotron experiments at Elettra (Italy) and was inspired by analyser-based methods [150. The typical experimental set-up is reported in Figure 9a. A beam of synchrotron radiation, propagating from left to right, is shaped down to a narrow blade of radiation by an aperture. It then traverses the sample and impinges on the edge of a second aperture that is placed in front of 

properties of this type of imaging systems.

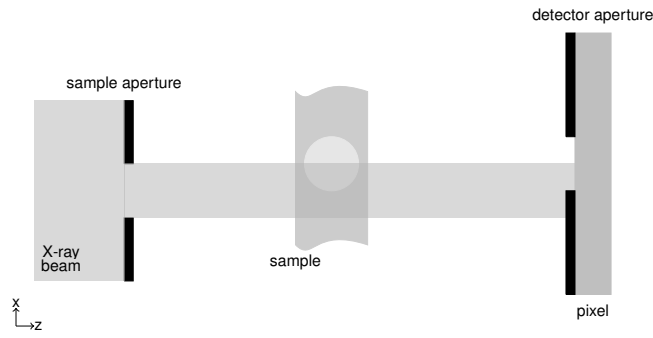

(a)

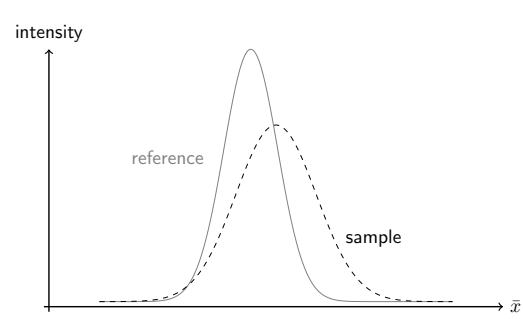

(b)

Figure 9: Edge illumination working principle: (a) typical synchrotron set-up and (b) illumination function.

the image receptor. If one of the two apertures is laterally shifted (along $x$ ) the recorded intensity is modulated: it reaches a maximum when the two apertures are perfectly aligned and it progressively decreases for increasing lateral shifts (see Figure 9b). This is often called illumination function and characterises the

,

The working principle of edge illumination can be explained by observing that refraction in the sample results in lateral shifts of the X-ray beam which are translated into intensity modulations by the presence of the second aperture. Referring to Figure 9a, a deflection upwards will result in an increased intensity at the detector pixel while a decreased intensity would be recorded if the deflection occurs downwards. This holds for a completely transparent object that only perturbs the phase of the X-ray beam. If the sample is also absorbing, then at least two images have to be acquired to extract the sample's absorption and refraction [151]. This is typically achieved by recording two intensity projections, with the apertures aligned in such a way that the shaped X-ray beam impinges on the two edges of the detector aperture. If the apertures are aligned such that half of the intensity reaches the detector in both cases, these two configurations correspond to the two points at the full width half maximum of the illumination function (see Figure $9 \mathrm{~b}$ ). The edge illumination principle can also be implemented with a laboratory set-up that uses rotating anode X-ray tubes with extended focal spots [152] (sketched in Figure 10). The diverging and 

mask that creates a series of independent beamlets. These propagate through

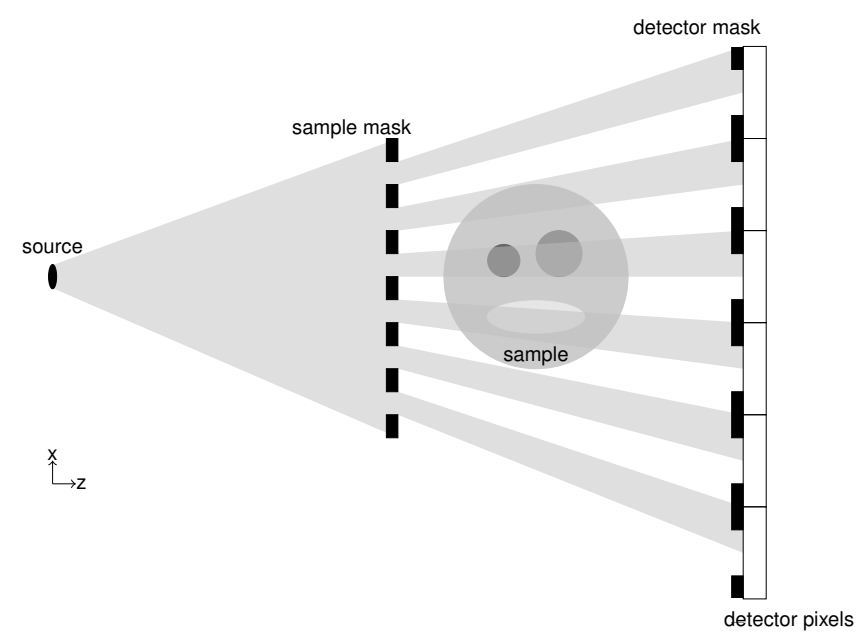

Figure 10: Laboratory set-up for edge illumination X-ray phase-contrast imaging.

346

polychromatic beam generated by this type of sources is shaped by a pre-sample

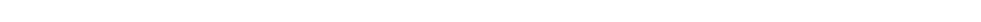

the sample and are then analysed by a second set of apertures before the detector. The pitches of both the pre-sample and the detector mask are harmonically matched to that of the detector pixels such that a one-to-one relationships exists between each aperture in both masks and each detector pixel column (along $y$ ). This approach has negligible spatial or temporal coherence requirements [153, 154], provides high sensitivity also for laboratory implementations [155, 156, enables the simultaneous attainment of high sensitivity and dynamic range [157, is robust against thermal and mechanical instabilities [158, 159] and the set-up can be made compact [160, 161]. By using a microfocal source it is possible to adopt a large magnification geometry and perform hard X-ray phase imaging with micrometre resolution [162. Two-dimensional sensitivity can be simultaneously achieved by using masks structured in two dimensions [163.

Dark-field images can be quantitatively retrieved by acquiring (at least) a third intensity projection [164, 165] and by using a Gaussian representation of the intensity. Under general conditions, the illumination function $L(\bar{x})$ (see 
Figure $9 \mathrm{~b}$ can be expressed in the following way

$$
I(\bar{x})=\sum_{m} \sum_{n} A_{m n} \exp \left[-\frac{\left(\bar{x}-\mu_{m n}\right)^{2}}{2 \sigma_{m n}^{2}}\right]
$$

where $\mu_{m n}=\mu_{m}+\mu_{n}, \sigma_{m n}^{2}=\sigma_{m}^{2}+\sigma_{n}^{2}$ and $A_{m n}=A_{m} A_{n}\left(1 / \sqrt{2 \pi \sigma_{m n}^{2}}\right)$. Both the illumination function $L(\bar{x})=\sum_{n}\left(A_{n} / \sqrt{2 \pi \sigma_{n}^{2}}\right) \exp \left[-\left(\bar{x}-\mu_{n}\right)^{2} / 2 \sigma_{n}^{2}\right]$ and the object function $O(\bar{x})=\sum_{m}\left(A_{m} / \sqrt{2 \pi \sigma_{m}^{2}}\right) \exp \left[-\left(\bar{x}-\mu_{m}\right)^{2} / 2 \sigma_{m}^{2}\right]$ have been represented as the sum of Gaussian functions, $(m=1 \ldots M$ and $n=1 \ldots N)$. A single-Gaussian representation of both illumination and object function is accurate in many practical cases and this allows for an analytic solution of Equation 23 [164. Should this not be the case, the number of terms to be retained in Equation 23 can be increased and the sample's parameters retrieved numerically [159, 166].

Tomographic edge-illumination X-ray phase-contrast imaging was developed at synchrotron sources [167] and adapted to rotating anode tubes [168, 169], including three-dimensional dark-field imaging [157]. A reverse-projection reconstruction method enabled a step change in the data acquisition strategy by allowing continuos rotation of the sample [170, 171]. More recent developments include algorithms for robust reconstructions [172, 173] and a single-image phase retrieval algorithm [174 that, albeit requiring homogeneity of the sample, greatly simplifies the practical implementation of the method especially with respect to tomography 175 . This can be extended to include multi-material samples 176 .

Examples of use in applied investigations of edge illumination X-ray phase contrast imaging are: low-dose mammography [177, 178, cartilage imaging [179, 180], security [181, baggage screening [182] with a large field of view scanning system [183 185], composites materials [186, 187, regenerative medicine [188] and lung imaging [189]. 


\section{Conclusion}

X-ray phase-contrast imaging can extend the applicability of radiography and tomography for visualising the internal structure of samples that do not exhibit enough absorption contrast. Various methods have been developed to obtain phase contrast images in the hard X-ray regime, and they were introduced and described along with examples of applications. The edge illumination approach, that has been subject of investigation and developments by our group in the recent years, was finally presented and discussed.

\section{Acknowledgements}

ME was supported by the Royal Academy of Engineering under the RAEng Research Fellowships scheme. Fruitful discussion with the members of the Advanced X-ray Imaging Group at UCL is kindly acknowledged.

[1] W. Röntgen, Über eine neue Art von Strahlen: vorläufige Mitteilung, Sitzungsber. Phys. Med. Gesell. (1895).

[2] G. N. Hounsfield, Computerized transverse axial scanning (tomography): Part 1. description of system, The British Journal of Radiology 46 (552) (1973) 1016-1022.

[3] S. Wilkins, Y. I. Nesterets, T. Gureyev, S. Mayo, A. Pogany, A. Stevenson, On the evolution and relative merits of hard x-ray phase-contrast imaging methods, Philosophical Transactions of the Royal Society of London A: Mathematical, Physical and Engineering Sciences 372 (2010) (2014) 20130021.

[4] A. Olivo, E. Castelli, X-ray phase contrast imaging: From synchrotrons to conventional sources, Rivista Del Nuovo Cimento 37 (9) (2014) 467-508.

[5] P. Suortti, W. Thomlinson, Medical applications of synchrotron radiation, Physics in medicine and biology 48 (13) (2003) R1. 
[6] R. Lewis, Medical phase contrast x-ray imaging: current status and future prospects, Physics in medicine and biology 49 (16) (2004) 3573.

[7] S.-A. Zhou, A. Brahme, Development of phase-contrast x-ray imaging techniques and potential medical applications, Physica Medica 24 (3) (2008) 129-148.

[8] A. Bravin, P. Coan, P. Suortti, X-ray phase-contrast imaging: from preclinical applications towards clinics, Physics in medicine and biology 58 (1) (2012) R1.

[9] P. Coan, A. Bravin, G. Tromba, Phase-contrast x-ray imaging of the breast: recent developments towards clinics, Journal of Physics D: Applied Physics 46 (49) (2013) 494007.

[10] A. Stevenson, T. Gureyev, D. Paganin, S. Wilkins, T. Weitkamp, A. Snigirev, C. Rau, I. Snigireva, H. Youn, I. Dolbnya, et al., Phase-contrast $\mathrm{x}$-ray imaging with synchrotron radiation for materials science applications, Nuclear Instruments and Methods in Physics Research Section B: Beam Interactions with Materials and Atoms 199 (2003) 427-435.

[11] S. C. Mayo, A. W. Stevenson, S. W. Wilkins, In-line phase-contrast xray imaging and tomography for materials science, Materials 5 (5) (2012) 937-965.

[12] T. E. Gureyev, Y. Nesterets, D. Ternovski, D. Thompson, S. W. Wilkins, A. W. Stevenson, A. Sakellariou, J. A. Taylor, Toolbox for advanced x-ray image processing, in: Proc Spie, Vol. 8141, 2011, pp. 81410B-14.

[13] M. Born, E. Wolf, Principles of optics: electromagnetic theory of propagation, interference and diffraction of light, Elsevier, 1980.

[14] M. Endrizzi, P. Oliva, B. Golosio, P. Delogu, Cmos aps detector characterization for quantitative x-ray imaging, Nuclear Instruments and Methods in Physics Research Section A: Accelerators, Spectrometers, Detectors and Associated Equipment 703 (2013) 26-32. 
[15] D. Paganin, Coherent X-ray optics, no. 6, Oxford University Press on Demand, 2006.

[16] R. James, The optical principles of the diffraction of x-rays, Bell and Sons, 1962.

[17] ICRU Tissue Substitutes in Radiation Dosimetry and Measurement, Report 44 of the International Commission on Radiation Units and Measurements, Bethesda, MD (1989).

[18] U. Bonse, M. Hart, An x-ray interferometer, Applied Physics Letters 6 (8) (1965) 155-156.

[19] U. Bonse, M. Hart, An x-ray interferometer with long separated interfering beam paths, Applied Physics Letters 7 (4) (1965) 99-100.

[20] M. Hart, U. Bonse, Interferometry with x rays, Physics Today 23 (8) (1970) 26-31.

[21] J. H. Bruning, D. R. Herriott, J. Gallagher, D. Rosenfeld, A. White, D. Brangaccio, Digital wavefront measuring interferometer for testing optical surfaces and lenses, Applied optics 13 (11) (1974) 2693-2703.

[22] M. Ando, S. Hosoya, An attempt at x-ray phase-contrast microscopy, in: Proceedings of the 6th International Conference on X-ray Optics and Microanalysis. Tokyo: University of Tokyo Press, 1972, pp. 63-68.

[23] M. Hart, Review lecture: Ten years of x-ray interferometry, in: Proceedings of the Royal Society of London A: Mathematical, Physical and Engineering Sciences, Vol. 346, The Royal Society, 1975, pp. 1-22.

[24] A. Momose, Demonstration of phase-contrast x-ray computed tomography using an x-ray interferometer, Nuclear Instruments and Methods in Physics Research Section A: Accelerators, Spectrometers, Detectors and Associated Equipment 352 (3) (1995) 622-628. 
[25] T. Takeda, A. Momose, Y. Itai, W. Jin, K. Hirano, Phase-contrast imaging with synchrotron x-rays for detecting cancer lesions, Academic radiology 2 (9) (1995) 799-803.

[26] A. Momose, T. Takeda, Y. Itai, Phase-contrast x-ray computed tomography for observing biological specimens and organic materials, Review of scientific instruments 66 (2) (1995) 1434-1436.

[27] A. Momose, T. Takeda, Y. Itai, K. Hirano, Phase-contrast x-ray computed tomography for observing biological soft tissues, Nature medicine 2 (4) (1996) 473-475.

[28] T. Takeda, A. Momose, E. Ueno, Y. Itai, Phase-contrast x-ray ct image of breast tumor, Journal of synchrotron radiation 5 (3) (1998) 1133-1135.

[29] A. Momose, J. Fukuda, Phase-contrast radiographs of nonstained rat cerebellar specimen, Medical physics 22 (4) (1995) 375-379.

[30] A. Momose, T. Takeda, Y. Itai, Contrast effect of blood on phase-contrast x-ray imaging, Academic radiology 2 (10) (1995) 883-887.

[31] A. Snigirev, I. Snigireva, V. Kohn, S. Kuznetsov, I. Schelokov, On the possibilities of x-ray phase contrast microimaging by coherent high-energy synchrotron radiation, Review of scientific instruments 66 (12) (1995) $5486-5492$.

[32] P. Cloetens, R. Barrett, J. Baruchel, J.-P. Guigay, M. Schlenker, Phase objects in synchrotron radiation hard x-ray imaging, Journal of Physics D: Applied Physics 29 (1) (1996) 133.

[33] S. Wilkins, T. E. Gureyev, D. Gao, A. Pogany, A. Stevenson, Phasecontrast imaging using polychromatic hard x-rays, Nature 384 (6607) (1996) 335.

[34] K. A. Nugent, Coherent methods in the x-ray sciences, Advances in Physics 59 (1) (2010) 1-99. 
[35] A. Pogany, D. Gao, S. Wilkins, Contrast and resolution in imaging with a microfocus x-ray source, Review of Scientific Instruments 68 (7) (1997) $2774-2782$.

[36] Y. I. Nesterets, S. Wilkins, T. Gureyev, A. Pogany, A. Stevenson, On the optimization of experimental parameters for x-ray in-line phase-contrast imaging, Review of scientific instruments 76 (9) (2005) 093706.

[37] T. E. Gureyev, Y. I. Nesterets, A. W. Stevenson, P. R. Miller, A. Pogany, S. W. Wilkins, Some simple rules for contrast, signal-to-noise and resolution in in-line x-ray phase-contrast imaging, Optics express 16 (5) (2008) $3223-3241$.

[38] K. Nugent, T. Gureyev, D. Cookson, D. Paganin, Z. Barnea, Quantitative phase imaging using hard x rays, Physical review letters 77 (14) (1996) 2961.

[39] T. Gureyev, S. Wilkins, On x-ray phase imaging with a point source, JOSA A 15 (3) (1998) 579-585.

[40] T. Gureyev, C. Raven, A. Snigirev, I. Snigireva, S. Wilkins, Hard xray quantitative non-interferometric phase-contrast microscopy, Journal of Physics D: Applied Physics 32 (5) (1999) 563.

[41] T. E. Gureyev, C. Raven, A. A. Snigirev, I. Snigireva, S. W. Wilkins, Hard x-ray quantitative noninterferometric phase-contrast imaging, in: Medical Imaging'99, International Society for Optics and Photonics, 1999, pp. 356364.

[42] T. Gureyev, S. Wilkins, On x-ray phase retrieval from polychromatic images, Optics communications 147 (4) (1998) 229-232.

[43] T. Gureyev, S. Mayo, S. Wilkins, D. Paganin, A. Stevenson, Quantitative in-line phase-contrast imaging with multienergy x rays, Physical Review Letters 86 (25) (2001) 5827. 
[44] P. Cloetens, W. Ludwig, J. Baruchel, D. Van Dyck, J. Van Landuyt, J. Guigay, M. Schlenker, Holotomography: Quantitative phase tomography with micrometer resolution using hard synchrotron radiation $\mathrm{x}$ rays, Applied physics letters 75 (19) (1999) 2912-2914.

[45] A. V. Bronnikov, Reconstruction formulas in phase-contrast tomography, Optics Communications 171 (4) (1999) 239-244.

[46] A. Barty, K. Nugent, A. Roberts, D. Paganin, Quantitative phase tomography, Optics Communications 175 (4) (2000) 329-336.

[47] D. Paganin, S. Mayo, T. E. Gureyev, P. R. Miller, S. W. Wilkins, Simultaneous phase and amplitude extraction from a single defocused image of a homogeneous object, Journal of microscopy 206 (1) (2002) 33-40.

[48] P. Cloetens, M. Pateyron-Salomé, J. Buffiere, G. Peix, J. Baruchel, F. Peyrin, M. Schlenker, Observation of microstructure and damage in materials by phase sensitive radiography and tomography, Journal of Applied Physics 81 (9) (1997) 5878-5886.

[49] J.-Y. Buffière, E. Maire, P. Cloetens, G. Lormand, R. Fougeres, Characterization of internal damage in a mmc $\mathrm{p}$ using $\mathrm{x}$-ray synchrotron phase contrast microtomography, Acta materialia 47 (5) (1999) 1613-1625.

[50] P. Spanne, C. Raven, I. Snigireva, A. Snigirev, In-line holography and phase-contrast microtomography with high energy x-rays, Physics in Medicine and Biology 44 (3) (1999) 741.

[51] P. Bleuet, P. Cloetens, P. Gergaud, D. Mariolle, N. Chevalier, R. Tucoulou, J. Susini, A. Chabli, A hard x-ray nanoprobe for scanning and projection nanotomography, Review of scientific instruments 80 (5) (2009) 056101.

[52] M. Langer, A. Pacureanu, H. Suhonen, Q. Grimal, P. Cloetens, F. Peyrin, X-ray phase nanotomography resolves the $3 \mathrm{~d}$ human bone ultrastructure, PloS one 7 (8) (2012) e35691. 
[53] H. Suhonen, F. Xu, L. Helfen, C. Ferrero, P. Vladimirov, P. Cloetens, Xray phase contrast and fluorescence nanotomography for material studies, International Journal of Materials Research 103 (2) (2012) 179-183.

[54] P. Varga, A. Pacureanu, M. Langer, H. Suhonen, B. Hesse, Q. Grimal, P. Cloetens, K. Raum, F. Peyrin, Investigation of the three-dimensional orientation of mineralized collagen fibrils in human lamellar bone using synchrotron x-ray phase nano-tomography, Acta biomaterialia 9 (9) (2013) 8118-8127.

[55] M. Kitchen, D. Paganin, R. Lewis, N. Yagi, K. Uesugi, S. Mudie, On the origin of speckle in x-ray phase contrast images of lung tissue, Physics in medicine and biology 49 (18) (2004) 4335.

[56] S. B. Hooper, M. J. Kitchen, M. J. Wallace, N. Yagi, K. Uesugi, M. J. Morgan, C. Hall, K. K. Siu, I. M. Williams, M. Siew, et al., Imaging lung aeration and lung liquid clearance at birth, The FASEB Journal 21 (12) (2007) 3329-3337.

[57] M. Kitchen, R. Lewis, M. Morgan, M. Wallace, M. Siew, K. Siu, A. Habib, A. Fouras, N. Yagi, K. Uesugi, et al., Dynamic measures of regional lung air volume using phase contrast x-ray imaging, Physics in medicine and biology 53 (21) (2008) 6065 .

[58] M. Kitchen, R. Lewis, N. Yagi, K. Uesugi, D. Paganin, S. Hooper, G. Adams, S. Jureczek, J. Singh, C. Christensen, et al., Phase contrast x-ray imaging of mice and rabbit lungs: a comparative study, The British journal of radiology.

[59] R. P. Murrie, K. S. Morgan, A. Maksimenko, A. Fouras, D. M. Paganin, C. Hall, K. K. Siu, D. W. Parsons, M. Donnelley, Live small-animal xray lung velocimetry and lung micro-tomography at the australian synchrotron imaging and medical beamline, Journal of synchrotron radiation 22 (4) (2015) 1049-1055. 
[60] M. Di Michiel, A. Olivo, G. Tromba, F. Arfelli, V. Bonvicini, A. Bravin, G. Cantatore, E. Castelli, L. D. Palma, R. Longo, S. Pani, D. Pontoni, P. Poropat, M. Prest, A. Rashevsky, A. Vacchi, E. Vallazza, Phase Contrast Imaging in the Field of Mammography, Springer Japan, Tokyo, 1998, pp. $78-82$.

[61] F. Arfelli, M. Assante, V. Bonvicini, A. Bravin, G. Cantatore, E. Castelli, L. D. Palma, M. D. Michiel, R. Longo, A. Olivo, S. Pani, D. Pontoni, P. Poropat, M. Prest, A. Rashevsky, G. Tromba, A. Vacchi, E. Vallazza, F. Zanconati, Low-dose phase contrast x-ray medical imaging, Physics in Medicine and Biology 43 (10) (1998) 2845.

[62] E. Castelli, F. Arfelli, D. Dreossi, R. Longo, T. Rokvic, M. Cova, E. Quaia, M. Tonutti, F. Zanconati, A. Abrami, et al., Clinical mammography at the syrmep beam line, Nuclear Instruments and Methods in Physics Research Section A: Accelerators, Spectrometers, Detectors and Associated Equipment 572 (1) (2007) 237-240.

[63] E. Castelli, M. Tonutti, F. Arfelli, R. Longo, E. Quaia, L. Rigon, D. Sanabor, F. Zanconati, D. Dreossi, A. Abrami, et al., Mammography with synchrotron radiation: first clinical experience with phase-detection technique, Radiology 259 (3) (2011) 684-694.

[64] R. Longo, M. Tonutti, L. Rigon, F. Arfelli, D. Dreossi, E. Quai, F. Zanconati, E. Castelli, G. Tromba, M. A. Cova, Clinical study in phasecontrast mammography: image-quality analysis, Philosophical Transactions of the Royal Society of London A: Mathematical, Physical and Engineering Sciences 372 (2010) (2014) 20130025.

[65] F. Arfelli, V. Bonvicini, A. Bravin, G. Cantatore, E. Castelli, L. D. Palma, M. D. Michiel, M. Fabrizioli, R. Longo, R. H. Menk, et al., Mammography with synchrotron radiation: Phase-detection techniques 1, Radiology 215 (1) (2000) 286-293. 
[66] K. Goetz, M. Kalashnikov, Y. A. Mikhailov, G. V. Sklizkov, S. Fedotov, E. Foerster, P. Zaumseil, Measurements of the parameters of shell targets for laser thermonuclear fusion using an x-ray schlieren method, Soviet Journal of Quantum Electronics 9 (5) (1979) 607.

[67] E. Forster, K. Goetz, P. Zaumseil, Double crystal diffractometry for the characterization of targets for laser fusion experiments, Kristall und Technik 15 (8) (1980) 937-945.

[68] T. Davis, D. Gao, T. Gureyev, A. Stevenson, S. Wilkins, et al., Phasecontrast imaging of weakly absorbing materials using hard x-rays, Nature 373 (6515) (1995) 595-598.

[69] V. Ingal, E. Beliaevskaya, X-ray plane-wave topography observation of the phase contrast from a non-crystalline object, Journal of Physics D: Applied Physics 28 (11) (1995) 2314.

[70] D. Chapman, W. Thomlinson, R. Johnston, D. Washburn, E. Pisano, N. Gmür, Z. Zhong, R. Menk, F. Arfelli, D. Sayers, Diffraction enhanced x-ray imaging, Physics in medicine and biology 42 (11) (1997) 2015.

[71] F. Dilmanian, Z. Zhong, B. Ren, X. Wu, L. Chapman, I. Orion, W. Thomlinson, Computed tomography of x-ray index of refraction using the diffraction enhanced imaging method, Physics in medicine and biology 45 (4) (2000) 933.

[72] Y. I. Nesterets, T. Gureyev, D. Paganin, K. Pavlov, S. Wilkins, Quantitative diffraction-enhanced x-ray imaging of weak objects, Journal of Physics D: Applied Physics 37 (8) (2004) 1262.

[73] T. Gureyev, S. Wilkins, Regimes of x-ray phase-contrast imaging with perfect crystals, Il Nuovo Cimento D 19 (2) (1997) 545-552.

[74] M. N. Wernick, O. Wirjadi, D. Chapman, Z. Zhong, N. P. Galatsanos, Y. Yang, J. G. Brankov, O. Oltulu, M. A. Anastasio, C. Muehleman, 
Multiple-image radiography, Physics in medicine and biology 48 (23) (2003) 3875 .

[75] O. Oltulu, Z. Zhong, M. Hasnah, M. N. Wernick, D. Chapman, Extraction of extinction, refraction and absorption properties in diffraction enhanced imaging, Journal of Physics D: Applied Physics 36 (17) (2003) 2152.

[76] L. Rigon, H.-J. Besch, F. Arfelli, R.-H. Menk, G. Heitner, H. PlothowBesch, A new dei algorithm capable of investigating sub-pixel structures, Journal of Physics D: Applied Physics 36 (10A) (2003) A107.

[77] E. Pagot, P. Cloetens, S. Fiedler, A. Bravin, P. Coan, J. Baruchel, J. Härtwig, W. Thomlinson, A method to extract quantitative information in analyzer-based x-ray phase contrast imaging, Applied Physics Letters 82 (20) (2003) 3421-3423.

[78] L. Rigon, A. Astolfo, F. Arfelli, R.-H. Menk, Generalized diffraction enhanced imaging: application to tomography, European journal of radiology 68 (3) (2008) S3-S7.

[79] M. J. Kitchen, D. M. Paganin, K. Uesugi, B. J. Allison, R. A. Lewis, S. B. Hooper, K. M. Pavlov, X-ray phase, absorption and scatter retrieval using two or more phase contrast images, Optics express 18 (19) (2010) 19994-20012.

[80] D. Chapman, E. Pisano, W. Thomlinson, Z. Zhong, R. Johnston, D. Washburn, D. Sayers, K. Malinowska, Medical applications of diffraction enhanced imaging, Breast Disease 10 (3-4) (1998) 197-207.

[81] J. Mollenhauer, M. Aurich, Z. Zhong, C. Muehleman, A. Cole, M. Hasnah, O. Oltulu, K. Kuettner, A. Margulis, L. Chapman, Diffraction-enhanced $\mathrm{x}$-ray imaging of articular cartilage, Osteoarthritis and cartilage 10 (3) (2002) 163-171.

[82] P. Coan, F. Bamberg, P. C. Diemoz, A. Bravin, K. Timpert, E. Mützel, J. G. Raya, S. Adam-Neumair, M. F. Reiser, C. Glaser, Characterization 
of osteoarthritic and normal human patella cartilage by computed tomography x-ray phase-contrast imaging: a feasibility study, Investigative radiology 45 (7) (2010) 437-444.

[83] P. Coan, A. Wagner, A. Bravin, P. C. Diemoz, J. Keyriläinen, J. Mollenhauer, In vivo x-ray phase contrast analyzer-based imaging for longitudinal osteoarthritis studies in guinea pigs, Physics in medicine and biology 55 (24) (2010) 7649.

[84] C. Muehleman, J. Li, D. Connor, C. Parham, E. Pisano, Z. Zhong, Diffraction-enhanced imaging of musculoskeletal tissues using a conventional x-ray tube, Academic radiology 16 (8) (2009) 918-923.

[85] V. N. Ingal, E. A. Beliaevskaya, A. P. Brianskaya, R. D. Merkurieva, Phase mammography-a new technique for breast investigation, Physics in medicine and biology 43 (9) (1998) 2555.

[86] E. D. Pisano, R. E. Johnston, D. Chapman, J. Geradts, M. V. Iacocca, C. A. Livasy, D. B. Washburn, D. E. Sayers, Z. Zhong, M. Z. Kiss, et al., Human breast cancer specimens: Diffraction-enhanced imaging with histologic correlation?improved conspicuity of lesion detail compared with digital radiography 1, Radiology 214 (3) (2000) 895-901.

[87] A. Sztrókay, P. Diemoz, T. Schlossbauer, E. Brun, F. Bamberg, D. Mayr, M. Reiser, A. Bravin, P. Coan, High-resolution breast tomography at high energy: a feasibility study of phase contrast imaging on a whole breast, Physics in medicine and biology 57 (10) (2012) 2931.

[88] T. Millard, M. Endrizzi, L. Rigon, F. Arfelli, R. Menk, J. Owen, E. Stride, A. Olivo, Quantification of microbubble concentration through x-ray phase contrast imaging, Applied Physics Letters 103 (11) (2013) 114105.

[89] T. Millard, M. Endrizzi, N. Everdell, L. Rigon, F. Arfelli, R. Menk, E. Stride, A. Olivo, Evaluation of microbubble contrast agents for dynamic imaging with x-ray phase contrast, Scientific reports 5 . 
[90] F. Pfeiffer, A. Momose, W. Yashiro, Milestones and basic principles of grating-based x-ray and neutron phase-contrast imaging, in: AIP Conference Proceedings, Vol. 1466, AIP, 2012, pp. 2-11.

[91] J. Clauser, M. Reinsch, New theoretical and experimental results in fresnel optics with applications to matter-wave and x-ray interferometry, Applied Physics B: Lasers and Optics 54 (5) (1992) 380-395.

[92] J. F. Clauser, Ultrahigh resolution interferometric x-ray imaging, US Patent 5,812,629.

[93] P. Cloetens, J. Guigay, C. De Martino, J. Baruchel, M. Schlenker, Fractional talbot imaging of phase gratings with hard $\mathrm{x}$ rays, Optics letters 22 (14) (1997) 1059-1061.

[94] P. Cloetens, J.-P. Guigay, C. De Martino, M. Pateyron-Salome, M. Schlenker, D. Van Dyck, Quantitative aspects of coherent hard xray imaging: Talbot images and holographic reconstruction, in: Optical Science, Engineering and Instrumentation'97, International Society for Optics and Photonics, 1997, pp. 72-82.

[95] C. David, B. Nöhammer, H. Solak, E. Ziegler, Differential x-ray phase contrast imaging using a shearing interferometer, Applied physics letters 81 (17) (2002) 3287-3289.

[96] A. Momose, S. Kawamoto, I. Koyama, Y. Hamaishi, K. Takai, Y. Suzuki, Demonstration of x-ray talbot interferometry, Japanese journal of applied physics 42 (7B) (2003) L866.

[97] T. Weitkamp, A. Diaz, C. David, F. Pfeiffer, M. Stampanoni, P. Cloetens, E. Ziegler, X-ray phase imaging with a grating interferometer, Optics express 13 (16) (2005) 6296-6304.

[98] F. Pfeiffer, T. Weitkamp, O. Bunk, C. David, Phase retrieval and differential phase-contrast imaging with low-brilliance x-ray sources, Nature physics 2 (4) (2006) 258-261. 
[99] F. Pfeiffer, C. Kottler, O. Bunk, C. David, Hard x-ray phase tomography with low-brilliance sources, Physical review letters 98 (10) (2007) 108105.

[100] F. Pfeiffer, M. Bech, O. Bunk, P. Kraft, E. F. Eikenberry, C. Brönnimann, C. Grünzweig, C. David, Hard-x-ray dark-field imaging using a grating interferometer, Nature materials 7 (2) (2008) 134-137.

[101] Z.-F. Huang, K.-J. Kang, L. Zhang, Z.-Q. Chen, F. Ding, Z.-T. Wang, Q.G. Fang, Alternative method for differential phase-contrast imaging with weakly coherent hard x rays, Physical Review A 79 (1) (2009) 013815.

[102] Z.-T. Wang, K.-J. Kang, Z.-F. Huang, Z.-Q. Chen, Quantitative gratingbased x-ray dark-field computed tomography, Applied Physics Letters 95 (9) (2009) 094105.

[103] M. Bech, O. Bunk, T. Donath, R. Feidenhans, C. David, F. Pfeiffer, Quantitative x-ray dark-field computed tomography, Physics in medicine and biology 55 (18) (2010) 5529.

[104] I. Zanette, T. Weitkamp, T. Donath, S. Rutishauser, C. David, Twodimensional x-ray grating interferometer, Physical review letters 105 (24) (2010) 248102.

[105] H. Itoh, K. Nagai, G. Sato, K. Yamaguchi, T. Nakamura, T. Kondoh, C. Ouchi, T. Teshima, Y. Setomoto, T. Den, Two-dimensional gratingbased $\mathrm{X}$-ray phase-contrast imaging using fourier transform phase retrieval, Optics express 19 (4) (2011) 3339-3346.

[106] G. Sato, T. Kondoh, H. Itoh, S. Handa, K. Yamaguchi, T. Nakamura, K. Nagai, C. Ouchi, T. Teshima, Y. Setomoto, et al., Two-dimensional gratings-based phase-contrast imaging using a conventional x-ray tube, Optics letters 36 (18) (2011) 3551-3553.

[107] B. Wu, Y. Liu, C. Rose-Petruck, G. J. Diebold, X-ray spatial frequency heterodyne imaging, Applied Physics Letters 100 (6) (2012) 061110. 
[108] T. Donath, M. Chabior, F. Pfeiffer, O. Bunk, E. Reznikova, J. Mohr, E. Hempel, S. Popescu, M. Hoheisel, M. Schuster, et al., Inverse geometry for grating-based x-ray phase-contrast imaging, Journal of Applied Physics 106 (5) (2009) 054703.

[109] N. Morimoto, S. Fujino, K.-i. Ohshima, J. Harada, T. Hosoi, H. Watanabe, T. Shimura, X-ray phase contrast imaging by compact talbot-lau interferometer with a single transmission grating, Optics letters 39 (15) (2014) 4297-4300.

[110] H. Miao, A. A. Gomella, N. Chedid, L. Chen, H. Wen, Fabrication of 200 $\mathrm{nm}$ period hard x-ray phase gratings, Nano letters 14 (6) (2014) 3453.

[111] H. Miao, A. A. Gomella, K. J. Harmon, E. E. Bennett, N. Chedid, S. Znati, A. Panna, B. A. Foster, P. Bhandarkar, H. Wen, Enhancing tabletop x-ray phase contrast imaging with nano-fabrication, Scientific reports 5.

[112] H. Miao, A. Panna, A. A. Gomella, E. E. Bennett, S. Znati, L. Chen, H. Wen, A universal moiré effect and application in x-ray phase-contrast imaging, Nature physics 12 (9) (2016) 830-834.

[113] Z. Wang, N. Hauser, G. Singer, M. Trippel, R. A. Kubik-Huch, C. W. Schneider, M. Stampanoni, Non-invasive classification of microcalcifications with phase-contrast x-ray mammography, Nature communications 5.

[114] T. Michel, J. Rieger, G. Anton, F. Bayer, M. W. Beckmann, J. Durst, P. A. Fasching, W. Haas, A. Hartmann, G. Pelzer, et al., On a darkfield signal generated by micrometer-sized calcifications in phase-contrast mammography, Physics in medicine and biology 58 (8) (2013) 2713.

[115] M. Stampanoni, Z. Wang, T. Thüring, C. David, E. Roessl, M. Trippel, R. A. Kubik-Huch, G. Singer, M. K. Hohl, N. Hauser, The first analysis and clinical evaluation of native breast tissue using differential phasecontrast mammography, Investigative radiology 46 (12) (2011) 801-806. 
[116] F. Pfeiffer, O. Bunk, C. David, M. Bech, G. Le Duc, A. Bravin, P. Cloetens, High-resolution brain tumor visualization using threedimensional x-ray phase contrast tomography, Physics in medicine and biology 52 (23) (2007) 6923.

[117] A. Momose, W. Yashiro, K. Kido, J. Kiyohara, C. Makifuchi, T. Ito, S. Nagatsuka, C. Honda, D. Noda, T. Hattori, et al., X-ray phase imaging: from synchrotron to hospital, Phil. Trans. R. Soc. A 372 (2010) (2014) 20130023.

[118] J. Tanaka, M. Nagashima, K. Kido, Y. Hoshino, J. Kiyohara, C. Makifuchi, S. Nishino, S. Nagatsuka, A. Momose, Cadaveric and in vivo human joint imaging based on differential phase contrast by x-ray talbot-lau interferometry, Zeitschrift für medizinische Physik 23 (3) (2013) 222-227.

[119] D. Stutman, T. J. Beck, J. A. Carrino, C. O. Bingham, Talbot phasecontrast x-ray imaging for the small joints of the hand, Physics in medicine and biology 56 (17) (2011) 5697.

[120] T. Thüring, R. Guggenberger, H. Alkadhi, J. Hodler, M. Vich, Z. Wang, C. David, M. Stampanoni, Human hand radiography using x-ray differential phase contrast combined with dark-field imaging, Skeletal radiology 42 (6) (2013) 827-835.

[121] S. Schleede, F. G. Meinel, M. Bech, J. Herzen, K. Achterhold, G. Potdevin, A. Malecki, S. Adam-Neumair, S. F. Thieme, F. Bamberg, et al., Emphysema diagnosis using x-ray dark-field imaging at a laser-driven compact synchrotron light source, Proceedings of the National Academy of Sciences 109 (44) (2012) 17880-17885.

[122] M. Bech, A. Tapfer, A. Velroyen, A. Yaroshenko, B. Pauwels, J. Hostens, P. Bruyndonckx, A. Sasov, F. Pfeiffer, In-vivo dark-field and phasecontrast x-ray imaging, Scientific reports 3 (2013) 3209. 
[123] F. Pfeiffer, J. Herzen, M. Willner, M. Chabior, S. Auweter, M. Reiser, F. Bamberg, Grating-based x-ray phase contrast for biomedical imaging applications, Zeitschrift für medizinische Physik 23 (3) (2013) 176-185.

[124] S. Wilkins, Improved x-ray optics, especially for phase-contrast imaging, International patent WO 1995005725 (1995) A1.

[125] S. Wilkins, On a spatially resolving usaxs instrument for operation at a third-generation synchrotron radiation source, Journal of synchrotron radiation 5 (3) (1998) 986-988.

[126] S. C. Mayo, B. Sexton, Refractive microlens array for wave-front analysis in the medium to hard x-ray range, Optics letters 29 (8) (2004) 866-868.

[127] M. De Jonge, B. Hornberger, C. Holzner, D. Legnini, D. Paterson, I. McNulty, C. Jacobsen, S. Vogt, Quantitative phase imaging with a scanning transmission x-ray microscope, Physical review letters 100 (16) (2008) 163902.

[128] K. S. Morgan, D. M. Paganin, K. K. Siu, Quantitative single-exposure xray phase contrast imaging using a single attenuation grid, Optics express 19 (20) (2011) 19781-19789.

[129] F. A. Vittoria, M. Endrizzi, P. C. Diemoz, U. H. Wagner, C. Rau, I. K. Robinson, A. Olivo, Virtual edge illumination and one dimensional beam tracking for absorption, refraction, and scattering retrieval, Applied Physics Letters 104 (13) (2014) 134102.

[130] F. A. Vittoria, G. K. Kallon, D. Basta, P. C. Diemoz, I. K. Robinson, A. Olivo, M. Endrizzi, Beam tracking approach for single-shot retrieval of absorption, refraction, and dark-field signals with laboratory $\mathrm{x}$-ray sources, Applied Physics Letters 106 (22) (2015) 224102.

[131] K. S. Morgan, D. M. Paganin, K. K. Siu, Quantitative x-ray phasecontrast imaging using a single grating of comparable pitch to sample feature size, Optics letters 36 (1) (2011) 55-57. 
[132] R. Cerbino, L. Peverini, M. Potenza, A. Robert, P. Bösecke, M. Giglio, X-ray-scattering information obtained from near-field speckle, Nature Physics 4 (3) (2008) 238-243.

[133] K. S. Morgan, D. M. Paganin, K. K. Siu, X-ray phase imaging with a paper analyzer, Applied Physics Letters 100 (12) (2012) 124102.

[134] F. Krejci, J. Jakubek, M. Kroupa, Hard x-ray phase contrast imaging using single absorption grating and hybrid semiconductor pixel detector, Review of Scientific Instruments 81 (11) (2010) 113702.

[135] H. Wen, E. E. Bennett, M. M. Hegedus, S. C. Carroll, Spatial harmonic imaging of x-ray scattering?initial results, IEEE transactions on medical imaging 27 (8) (2008) 997-1002.

[136] H. H. Wen, E. E. Bennett, R. Kopace, A. F. Stein, V. Pai, Single-shot x-ray differential phase-contrast and diffraction imaging using two-dimensional transmission gratings, Optics letters 35 (12) (2010) 1932-1934.

[137] F. Krejci, J. Jakubek, M. Kroupa, Low dose x-ray phase contrast imaging sensitive to phase effects in 2-d, in: Nuclear Science Symposium Conference Record (NSS/MIC), 2010 IEEE, IEEE, 2010, pp. 2194-2199.

[138] S. Bérujon, E. Ziegler, R. Cerbino, L. Peverini, Two-dimensional x-ray beam phase sensing, Physical review letters 108 (15) (2012) 158102.

[139] S. Berujon, H. Wang, K. Sawhney, X-ray multimodal imaging using a random-phase object, Physical Review A 86 (6) (2012) 063813.

[140] I. Zanette, T. Zhou, A. Burvall, U. Lundström, D. H. Larsson, M. Zdora, P. Thibault, F. Pfeiffer, H. M. Hertz, Speckle-based x-ray phase-contrast and dark-field imaging with a laboratory source, Physical review letters 112 (25) (2014) 253903.

[141] T. H. Jensen, M. Bech, O. Bunk, T. Donath, C. David, R. Feidenhans, F. Pfeiffer, Directional x-ray dark-field imaging, Physics in medicine and biology 55 (12) (2010) 3317. 
[142] H. Wang, S. Berujon, J. Herzen, R. Atwood, D. Laundy, A. Hipp, K. Sawhney, X-ray phase contrast tomography by tracking near field speckle, Scientific reports 5 (2015) 8762 .

[143] M. Kagias, Z. Wang, P. Villanueva-Perez, K. Jefimovs, M. Stampanoni, 2d-omnidirectional hard-x-ray scattering sensitivity in a single shot, Physical review letters 116 (9) (2016) 093902.

[144] F. A. Vittoria, M. Endrizzi, P. C. Diemoz, A. Zamir, U. H. Wagner, C. Rau, I. K. Robinson, A. Olivo, X-ray absorption, phase and dark-field tomography through a beam tracking approach, Scientific reports 5 (2015) 16318 .

[145] H. Wen, E. E. Bennett, M. M. Hegedus, S. Rapacchi, Fourier x-ray scattering radiography yields bone structural information 1, Radiology 251 (3) (2009) 910-918.

[146] K. S. Morgan, M. Donnelley, D. M. Paganin, A. Fouras, N. Yagi, Y. Suzuki, A. Takeuchi, K. Uesugi, R. C. Boucher, D. W. Parsons, et al., Measuring airway surface liquid depth in ex vivo mouse airways by x-ray imaging for the assessment of cystic fibrosis airway therapies, PloS one 8 (1) (2013) e55822.

[147] K. S. Morgan, M. Donnelley, N. Farrow, A. Fouras, N. Yagi, Y. Suzuki, A. Takeuchi, K. Uesugi, R. C. Boucher, K. K. Siu, et al., In vivo xray imaging reveals improved airway surface hydration after a therapy designed for cystic fibrosis, American journal of respiratory and critical care medicine 190 (4) (2014) 469-472.

[148] S. Berujon, H. Wang, S. Alcock, K. Sawhney, At-wavelength metrology of hard x-ray mirror using near field speckle, Optics express 22 (6) (2014) 6438-6446.

[149] S. Berujon, E. Ziegler, P. Cloetens, X-ray pulse wavefront metrology using speckle tracking, Journal of synchrotron radiation 22 (4) (2015) 886-894. 
[150] A. Olivo, F. Arfelli, G. Cantatore, R. Longo, R. Menk, S. Pani, M. Prest, P. Poropat, L. Rigon, G. Tromba, et al., An innovative digital imaging set-up allowing a low-dose approach to phase contrast applications in the medical field, Medical physics 28 (8) (2001) 1610-1619.

[151] P. R. Munro, K. Ignatyev, R. D. Speller, A. Olivo, Phase and absorption retrieval using incoherent x-ray sources, Proceedings of the National Academy of Sciences 109 (35) (2012) 13922-13927.

[152] A. Olivo, R. Speller, A coded-aperture technique allowing x-ray phase contrast imaging with conventional sources, Applied Physics Letters 91 (7) (2007) 074106.

[153] P. R. Munro, K. Ignatyev, R. D. Speller, A. Olivo, Source size and temporal coherence requirements of coded aperture type x-ray phase contrast imaging systems., Optics express 18 (19) (2010) 19681-19692.

[154] M. Endrizzi, F. A. Vittoria, G. Kallon, D. Basta, P. C. Diemoz, A. Vincenzi, P. Delogu, R. Bellazzini, A. Olivo, Achromatic approach to phasebased multi-modal imaging with conventional x-ray sources, Optics express 23 (12) (2015) 16473-16480.

[155] P. Diemoz, M. Endrizzi, C. Zapata, Z. Pešić, C. Rau, A. Bravin, I. Robinson, A. Olivo, X-ray phase-contrast imaging with nanoradian angular resolution, Physical review letters 110 (13) (2013) 138105.

[156] P. Diemoz, C. Hagen, M. Endrizzi, A. Olivo, Sensitivity of laboratory based implementations of edge illumination x-ray phase-contrast imaging, Applied Physics Letters 103 (24) (2013) 244104.

[157] M. Endrizzi, F. Vittoria, L. Rigon, D. Dreossi, F. Iacoviello, P. Shearing, A. Olivo, X-ray phase-contrast radiography and tomography with a multiaperture analyzer, Physical Review Letters 118 (24) (2017) 243902.

[158] T. Millard, M. Endrizzi, K. Ignatyev, C. Hagen, P. Munro, R. Speller, A. Olivo, Method for automatization of the alignment of a laboratory 
based x-ray phase contrast edge illumination system, Review of Scientific Instruments 84 (8) (2013) 083702.

[159] M. Endrizzi, D. Basta, A. Olivo, Laboratory-based x-ray phase-contrast imaging with misaligned optical elements, Applied Physics Letters 107 (12) (2015) 124103.

[160] D. Basta, M. Endrizzi, F. Vittoria, G. Kallon, T. Millard, P. Diemoz, A. Olivo, Note: Design and realization of a portable edge illumination xray phase contrast imaging system, Review of Scientific Instruments 86 (9) (2015) 096102.

[161] D. Basta, M. Endrizzi, F. Vittoria, A. Astolfo, A. Olivo, Compact and cost effective lab-based edge-illumination x-ray phase contrast imaging with a structured focal spot, Applied Physics Letters 108 (22) (2016) 224102.

[162] M. Endrizzi, F. A. Vittoria, P. C. Diemoz, R. Lorenzo, R. D. Speller, U. H. Wagner, C. Rau, I. K. Robinson, A. Olivo, Phase-contrast microscopy at high x-ray energy with a laboratory setup, Optics letters 39 (11) (2014) $3332-3335$.

[163] G. K. Kallon, M. Wesolowski, F. A. Vittoria, M. Endrizzi, D. Basta, T. P. Millard, P. C. Diemoz, A. Olivo, A laboratory based edge-illumination xray phase-contrast imaging setup with two-directional sensitivity, Applied Physics Letters 107 (20) (2015) 204105.

[164] M. Endrizzi, P. C. Diemoz, T. P. Millard, J. Louise Jones, R. D. Speller, I. K. Robinson, A. Olivo, Hard x-ray dark-field imaging with incoherent sample illumination, Applied Physics Letters 104 (2) (2014) 024106.

[165] M. Endrizzi, P. C. Diemoz, C. K. Hagen, T. P. Millard, F. A. Vittoria, U. H. Wagner, C. Rau, I. K. Robinson, A. Olivo, Laboratory-based edge-illumination phase-contrast imaging: Dark-field retrieval and highresolution implementations, in: Nuclear Science Symposium and Medical Imaging Conference (NSS/MIC), 2014 IEEE, IEEE, 2014, pp. 1-4. 
[166] A. Astolfo, M. Endrizzi, G. Kallon, T. P. Millard, F. A. Vittoria, A. Olivo, A first investigation of accuracy, precision and sensitivity of phase-based x-ray dark-field imaging, Journal of Physics D: Applied Physics 49 (48) (2016) 485501.

[167] C. Hagen, P. Diemoz, M. Endrizzi, L. Rigon, D. Dreossi, F. Arfelli, F. Lopez, R. Longo, A. Olivo, Theory and preliminary experimental verification of quantitative edge illumination x-ray phase contrast tomography, Optics express 22 (7) (2014) 7989-8000.

[168] C. Hagen, P. Munro, M. Endrizzi, P. Diemoz, A. Olivo, Low-dose phase contrast tomography with conventional x-ray sources, Medical physics $41(7)$.

[169] C. K. Hagen, A. Zamir, P. C. Diemoz, M. Endrizzi, F. Kennedy, R. H. Jager, A. Olivo, Low-dose x-ray phase contrast tomography: Experimental setup, image reconstruction and applications in biomedicine, in: Nuclear Science Symposium and Medical Imaging Conference (NSS/MIC), 2014 IEEE, IEEE, 2014, pp. 1-5.

[170] C. K. Hagen, M. Endrizzi, P. C. Diemoz, A. Olivo, Reverse projection retrieval in edge illumination x-ray phase contrast computed tomography, Journal of Physics D: Applied Physics 49 (25) (2016) 255501.

[171] C. K. Hagen, P. Maghsoudlou, G. Totonelli, P. C. Diemoz, M. Endrizzi, A. Zamir, P. Coan, A. Bravin, P. De Coppi, A. Olivo, Strategies for fast and low-dose laboratory-based phase contrast tomography for microstructural scaffold analysis in tissue engineering, in: SPIE Optical Engineering + Applications, International Society for Optics and Photonics, 2016, pp. 996705-996705.

[172] A. Zamir, M. Endrizzi, C. K. Hagen, F. A. Vittoria, L. Urbani, P. De Coppi, A. Olivo, Robust phase retrieval for high resolution edge illumination $\mathrm{x}$-ray phase-contrast computed tomography in non-ideal environments, Scientific Reports 6. 
[173] A. Zamir, C. K. Hagen, P. C. Diemoz, M. Endrizzi, F. A. Vittoria, L. Urbani, P. De Coppi, A. Olivo, Increased robustness and speed in low-dose phase-contrast tomography with laboratory sources, in: SPIE Optical Engineering+ Applications, International Society for Optics and Photonics, 2016, pp. 996716-996716.

[174] P. C. Diémoz, F. A. Vittoria, C. K. Hagen, M. Endrizzi, P. Coan, A. Bravin, U. H. Wagner, C. Rau, I. K. Robinson, A. Olivo, A single-image retrieval method for edge illumination x-ray phase-contrast imaging: application and noise analysis, Physica Medica 32 (12) (2016) 1759-1764.

[175] P. Diemoz, C. Hagen, M. Endrizzi, M. Minuti, R. Bellazzini, L. Urbani, P. De Coppi, A. Olivo, Single-shot x-ray phase-contrast computed tomography with nonmicrofocal laboratory sources, Physical Review Applied 7 (4) (2017) 044029.

[176] A. Zamir, P. C. Diemoz, F. A. Vittoria, C. K. Hagen, M. Endrizzi, A. Olivo, Edge illumination x-ray phase tomography of multi-material samples using a single-image phase retrieval algorithm, Optics Express 25 (10) (2017) 11984-11996.

[177] A. Olivo, S. Gkoumas, M. Endrizzi, C. Hagen, M. Szafraniec, P. Diemoz, P. Munro, K. Ignatyev, B. Johnson, J. Horrocks, et al., Low-dose phase contrast mammography with conventional x-ray sources, Medical physics 40 (9).

[178] P. C. Diemoz, A. Bravin, A. Sztrókay-Gaul, M. Ruat, S. Grandl, D. Mayr, S. Auweter, A. Mittone, E. Brun, C. Ponchut, et al., A method for high-energy, low-dose mammography using edge illumination x-ray phasecontrast imaging, Physics in Medicine and Biology 61 (24) (2016) 8750.

[179] M. Marenzana, C. K. Hagen, P. D. N. Borges, M. Endrizzi, M. B. Szafraniec, K. Ignatyev, A. Olivo, Visualization of small lesions in rat cartilage by means of laboratory-based x-ray phase contrast imaging, Physics in medicine and biology 57 (24) (2012) 8173. 
[180] M. Marenzana, C. K. Hagen, P. D. N. Borges, M. Endrizzi, M. B. Szafraniec, T. L. Vincent, L. Rigon, F. Arfelli, R.-H. Menk, A. Olivo, Synchrotron-and laboratory-based x-ray phase-contrast imaging for imaging mouse articular cartilage in the absence of radiopaque contrast agents, Philosophical Transactions of the Royal Society of London A: Mathematical, Physical and Engineering Sciences 372 (2010) (2014) 20130127.

[181] K. Ignatyev, P. Munro, D. Chana, R. Speller, A. Olivo, Coded apertures allow high-energy x-ray phase contrast imaging with laboratory sources, Journal of Applied Physics 110 (1) (2011) 014906.

[182] A. Astolfo, M. Endrizzi, B. Price, I. Haig, A. Olivo, The first largearea, high-x-ray energy phase contrast prototype for enhanced detection of threat objects in baggage screening, in: SPIE Security+ Defence, International Society for Optics and Photonics, 2016, pp. 999504-999504.

[183] M. Endrizzi, A. Astolfo, F. A. Vittoria, T. P. Millard, A. Olivo, Asymmetric masks for laboratory-based x-ray phase-contrast imaging with edge illumination, Scientific reports 6 .

[184] M. Endrizzi, A. Astolfo, B. Price, I. Haig, A. Olivo, Asymmetric masks for large field-of-view and high-energy x-ray phase contrast imaging, Journal of Instrumentation 11 (12) (2016) C12009.

[185] A. Astolfo, M. Endrizzi, F. A. Vittoria, P. C. Diemoz, B. Price, I. Haig, A. Olivo, Large field of view, fast and low dose multimodal phase-contrast imaging at high x-ray energy, Scientific Reports 7.

[186] M. Endrizzi, B. Murat, P. Fromme, A. Olivo, Edge-illumination x-ray dark-field imaging for visualising defects in composite structures, Composite Structures 134 (2015) 895-899.

[187] M. Endrizzi, A. Astolfo, B. Price, I. Haig, A. Olivo, Large field-of-view asymmetric masks for high-energy $\mathrm{x}$-ray phase imaging with standard $\mathrm{x}$ - 
ray tube, in: SPIE Optical Engineering+ Applications, International Society for Optics and Photonics, 2016, pp. 99640A-99640A.

[188] C. K. Hagen, P. Maghsoudlou, G. Totonelli, P. C. Diemoz, M. Endrizzi, L. Rigon, R.-H. Menk, F. Arfelli, D. Dreossi, E. Brun, et al., High contrast microstructural visualization of natural acellular matrices by means of phase-based x-ray tomography, Scientific reports 5 (2015) 18156.

[189] P. Modregger, T. P. Cremona, C. Benarafa, J. C. Schittny, A. Olivo, M. Endrizzi, Small angle x-ray scattering with edge-illumination, Scientific Reports 6. 